\title{
Helicobacter pylori e a atuação odontológica: revisão de literatura
}

\author{
Helicobacter pylori and dental practice: literature review \\ Helicobacter pylori y la prática dental: revisión de literatura
}

Maria Karoline Santos Silva Melo ${ }^{1 *}$, Alicya Morghana Silva Umbelino1, Isabela Braga Peixoto1, Laryssa Costa Canuto ${ }^{1}$, Ana Luiza Pontes de Oliveira ${ }^{1}$, Olívia Maria Guimarães Marroquim ${ }^{1}$, Diego Figueiredo Nóbrega ${ }^{1}$, Marćlíio Otávio Brandão Peixoto ${ }^{1}$, Fernanda Braga Peixoto¹.

\section{RESUMO}

Objetivo: Informar sobre a importância do trabalho odontológico na prevenção e tratamento da infecção pelo Helicobacter pylori. Revisão bibliográfica: Helicobacter pylori é uma bactéria gram-negativa que infecta humanos e tem potencial carcinogênico. As principais vias de transmissão desse patógeno são por meio de água ou alimentos contaminados ou via oral-oral. Normalmente, esse microrganismo se instala no estômago, porém a cavidade oral pode abrigá-lo temporariamente em nichos do biofilme dentário e gengival, saliva, língua, sulcos e até mesmo em condições relacionadas a processos inflamatórios como periodontites e úlceras aftosas. Assim, o H. pylori pode ser transmitido de um indivíduo para outro pela via oral-oral ou mesmo causar reinfecção em um paciente já infectado. Portanto, o controle especializado do biofilme dentário é um fator importante na prevenção e tratamento da infecção pelo Helicobacter pylori. Considerações finais: $O$ tratamento da infecção pelo Helicobacter pylori deve ser realizado de forma interdisciplinar entre o médico e o cirurgião-dentista, a fim de prevenir a transmissão do patógeno por via oral-oral e a reinfecção do paciente.

Palavras-chave: Helicobacter pylori, Odontologia, Periodontia.

\begin{abstract}
Objective: To inform about the importance of dental work in the prevention and treatment of Helicobacter pylori infection. Bibliographic review: Helicobacter pylori are a Gram-negative bacterium that infects humans and has a carcinogenic potential. The main routes of transmission of this pathogen are through contaminated water or food or oral-oral. Normally, this microorganism settles in the stomach, however, the oral cavity can temporarily shelter it in niches in the dental and gingival biofilm, saliva, tongue, grooves and even in conditions related to inflammatory processes such as periodontitis and aphthous ulcers. Thus, $H$. pylori can be transmitted from one individual to another through oral-oral means or even cause reinfection in an already infected patient. Therefore, specialized control of dental biofilm is an important factor in the prevention and treatment of Helicobacter pylori infection. Final considerations: The treatment of Helicobacter pylori infection should be done in an interdisciplinary way between the doctor and the dental surgeon in order to prevent the transmission of the pathogen by oral-oral route and the reinfection of the patient.
\end{abstract}

Keywords: Helicobacter pylori, Dentistry, Periodontics.

\section{RESUMEN}

Objetivo: Informar sobre la importancia del trabajo dental en la prevención y tratamiento de la infección por Helicobacter pylori. Revisión bibliográfica: Helicobacter pylori es una bacteria gramnegativa que infecta a los humanos y tiene potencial carcinogénico. Las principales vías de transmisión de este patógeno son a través de agua o alimentos contaminados u oral-oral. Normalmente, este microorganismo se instala en el

\footnotetext{
${ }^{1}$ Centro Universitário Cesmac, Maceió - AL. `E-mail: karolmelos@outlook.com
} 
estómago, sin embargo, la cavidad bucal puede albergarlo temporalmente en nichos del biofilm dental y gingival, saliva, lengua, surcos e incluso en afecciones relacionadas con procesos inflamatorios como periodontitis y úlceras aftosas. Así, $H$. pylori puede transmitirse de un individuo a otro por vía oral-oral o incluso provocar una reinfección en un paciente ya infectado. Por tanto, el control especializado del biofilm dental es un factor importante en la prevención y tratamiento de la infección por Helicobacter pylori. Consideraciones finales: El tratamiento de la infección por Helicobacter pylori debe realizarse de forma interdisciplinar entre el médico y el cirujano dentista con el fin de prevenir la transmisión del patógeno por vía oral-oral y la reinfección del paciente.

Palabras clave: Helicobacter pylori, Odontología, Periodoncia.

\section{INTRODUÇÃO}

Helicobacter pylori (H. pylori) é uma espécie constituinte da superfamília VI de bactérias gram-negativas. Caracteriza-se por sua motilidade, forma espiralada e multiflagelada. Essa bactéria infecta seres humanos e tem a capacidade de multiplicação em ambientes muito ácidos como o estômago. Isso se deve a sua capacidade de aderência e de produzir amônia, que é responsável pela neutralização da acidez do meio em questão. Ela foi registrada no ano de 1982 pelo médico australiano John Robin Warren, o que representa um importante feito para os estudos em saúde (SANTOS FG, 2017).

Esse patógeno (H. pylori) infecta metade da população mundial e está relacionado ao desenvolvimento de doenças como gastrite crônica, úlceras e cânceres gástricos, segundo Soyfoo DM, et al. (2021), e em 1994, foi considerado pela Organização Mundial da Saúde como um carcinógeno do tipo I para câncer gástrico - com destaque para o câncer intestinal (MEDINA ML, et al., 2017).

Condições socioeconômicas são consideradas fatores de risco para a infecção pela Helicobacter pylori. Em países subdesenvolvidos, a taxa de prevalência da infecção é maior devido principalmente às condições sanitárias em que vivem as pessoas dessas localidades (BARBOSA JA e SCHINONNI MI, 2011).

A contração da bactéria pode ocorrer durante a infância, no entanto, a infecção se desenvolve na fase adulta, evidenciada com associação com outros problemas do trato gastrointestinal. Segundo Santos MM, et al. (2015), as vias de transmissão mais comuns são gástrica-oral, devido ao refluxo; fecal-oral, por meio do contato com água contaminada com fezes que contém a bactéria; e oral-oral graças à resistência da Helicobacter pylori para sobreviver no biofilme bucal, segundo Santos FG, et al. (2017) como parte da população transitória ou mesmo permanente da cavidade oral (PARDO MLE, et al., 2011).

A boca é considerada o sítio mais relevante na disseminação de $H$. pylori por conta da influência com outros microrganismos do microbiota oral; e a inflamação dos tecidos periodontais propicia a adesão e detecção da bactéria nos tecidos bucais. Estudos demonstram que a boca serve como depósito por meio do biofilme dentário e da saliva, o que torna estas, materiais de referência para a detecção da bactéria em exames laboratoriais (JÚNIOR EGJ, et al., 2014). Diante da presença no ambiente oral, é possível afirmar que a boca serve como via de transmissão, infecção e reinfecção do indivíduo por esse patógeno (PEREIRA MF, et al., 2014).

O acúmulo de bactérias na superfície dos dentes na cavidade oral é o biofilme. Ele é adquirido independente da higienização regular, de acordo com Silva AS, et al. (2011), e a Helicobacter pylori é capaz de alocar-se nele e estabelecer relação com a doença periodontal, uma vez que a sua carga bacteriana na cavidade oral, é diretamente proporcional ao avanço da patologia (SANTOS MM, et al., 2015).

A forma correta de obter controle do biofilme é através da escovação que com as cerdas da escova causam um afastamento e removem depósitos microbianos. Somado a isso, deve-se empregar o uso do fio dental, que é responsável pela remoção do biofilme nos espaços interdentais e dessa maneira também contribui para prevenção de halitose, gengivite e cáries. O controle mecânico caseiro ou higienização bucal é a maneira mais simples de combater a placa bacteriana, prevenindo doenças periodontais inflamatórias e progressão de cáries, além de estabelecer a melhor relação entre o custo e o benefício para o paciente (SILVA AS, et al., 2011). 
Sendo assim, é de fundamental importância, além do tratamento médico, o tratamento do paciente com o periodontista para que seja feito o controle efetivo do biofilme dental afim de que, somado a orientação adequada de uma higienização eficaz, haja a eliminação de possíveis nichos na cavidade oral (SANTOS MM, et al., 2015).

O diagnóstico da infecção por Helicobacter pylori é feito através de endoscopia digestiva, seguida de estudo histológico, biópsias gástricas e teste de uréase. As formas não invasivas de diagnóstico incluem os testes respiratórios e sorológicos (SANTOS FG, 2017).

O tratamento convencional da infecção por $H$. pylori se faz por meio da combinação de medicamentos. No entanto, a bactéria pode adquirir resistência ao medicamento e, esse fator somado ao alto custo financeiro do tratamento, dificulta a sua acessibilidade e adesão em larga escala (MAGALHÃES CG, et al., 2016).

Assim, essa pesquisa tem o objetivo de informar sobre a importância do trabalho odontológico na prevenção e tratamento da infecção pelo Helicobacter pylori.

\section{REVISÃO BIBLIOGRÁFICA}

Helicobacter pylori mais comumente notada na forma de bacilo, é uma bactéria Gram-negativa, espiralada, urease-positiva, microaerofílica, multiflagelada e anaeróbica. Mede cerca de 0,5 $\mu \mathrm{m}$ a 0,9 $\mu \mathrm{m}$ de largura e de $2 \mu \mathrm{m}$ a $4 \mu \mathrm{m}$ de comprimento; Sua Motilidade flagelar é essencial na habilidade que a bactéria possui de locomoção no suco e muco gástrico, o que permite sua penetração na mucosa e sobrevivência do organismo no estômago humano (COELHO FMMC, 2013).

Possui um genoma circular constituído por mais de um milhão e meio de pares de bases de Ácido Desoxirribonucleico (DNA). Ao analisar as suas sequências de bases evidenciou-se que a bactéria possui sistemas de motilidade, homeostase do ferro e sistemas bem desenvolvidos para restrição e modificação do DNA, indicando significativa diversidade em muitas sequências gênicas, como as que codificam a urease, o flagelo, a proteína vacuolinizante e a citotoxina com associação ao gene $A$, que são considerados importantes fatores de virulência (RODRIGUES JA, et al., 2017).

De acordo com Santos MM et al. (2015), é comprovado que existe relação direta entre a bactéria e a gastrite crônica e aguda, que pode levar a úlceras gástrica e duodenal, câncer gástrico, linfoma do Tecido Linfoide Associado à Mucosa (MALT) e ainda, patologias externas ao sistema digestório como doenças cardiovasculares, diabetes, doenças imunológicas, inflamatórias e neoplásicas (JÚNIOR EGJ, et al., 2014).

A fisiopatologia da Helicobacter pylori e sua forma de expressão clínica decorrem de uma complexa interação entre ela e o indivíduo infectado. Dentre os fatores da bactéria, estão a oncoproteína CagA, exotoxina VacA, intervenção nas vias de apopotose e na acidez estomacal, citotoxinas inflamatórias, ação pró-trombótica e interferência no metabolismo do ferro (FERNANDES MJB, 2016).

A abertura da resposta inflamatória resulta dos fatores bacterianos, como urease e LPS (lipopolissacarídeo). As células epiteliais gástricas são os primeiros alvos da bactéria, pois expressam os receptores TLRs (Tool Like Receptors), que se unem à endotoxina LPS. Esta toxina é menos ativa na $H$. pylori comparado a outras bactérias gram-negativas, ou seja, é um ativador fraco da resposta imune do hospedeiro (COELHO FMMC, 2013).

O epitélio gástrico é estimulado pela bactéria a produzir citotoxinas como IL-8 (Interleucina 8), produtos de ativação do sistema complemento e leucotrienos, e surgem potentes quimiotáticos para os linfócitos e neutrófilos. O sistema celular e humoral é ativado pela bactéria e desenvolve uma resposta imunitária produzindo anticorpos anti-H.pylori, do tipo IgG (Imunoglobulina G) e IgA (Imunoglobulina A) e ativação dos linfócitos TH (T Helper). As células Th1 (T Helper 1) atraem células mononucleares para o local da infecção e produzem INF-y (Interferon-gama) que provoca a morte das células epiteliais (COELHO FMMC, 2013).

Estudos sugerem que hospedeiros da bactéria sejam mais propensos ao desenvolvimento de cardiopatias causadas por ateromas iniciados por meio das reações inflamatórias provenientes da 
Helicobacter pylori. Em contrapartida, essa hipótese causa discordância entre estudos que indicam que a eliminação do patógeno não é responsável por alterações bioquímicas ou metabólicas no organismo do hospedeiro. (GOMES LC e LAGO APMC, 2014).

A rota de transmissão de $H$. pylori ocorre por meio do contato inter hospedeiro e pela ingestão de alimentos ou água contaminados. Conforme Teixeira TF, et al. (2016) estabelece; ou seja, relaciona-se à falta de saneamento básico, de água potável, de higiene básica e condições de moradia (TABILE PM, et al., 2014). As formas de transmissão são as vias oral-oral, fecal-oral e iatrogênica - quando instrumentos são contaminados com secreções gástricas, sobretudo quando a lavagem do equipamento é manual principalmente em países em desenvolvimento (SANTOS MM, et al, 2015).

No entanto, a via fecal-oral é questionada por alguns autores, pois em um estudo, apenas $21 \%$ dos indivíduos testados manifestaram a bactéria em suas fezes; sendo a transmissão por êmese (vômito) mais provável devido a maior frequência do patógeno nas amostras coletadas para o estudo, comparada as amostras fecais (DRUMM B e ROWLAND M, 2011).

Além dessas formas de contágio, há a via gastro-gástrica, que ocorre quando o paciente é contaminado pelos equipamentos no momento do exame, quando estes não são devidamente higienizados (GOMES LC e LAGO APMC, 2014).

Grande parte da população adquire a infecção durante a faixa etária da infância de forma igual entre homens e mulheres e, se não tratada, pode permanecer por toda a vida do hospedeiro. Por isso a taxa de prevalência da infecção por Helicobacter pylori é cumulativa entre as parcelas da população (TEIXEIRA TF, et al., 2017).

Entretanto, os hospedeiros da bactéria podem ser assintomáticos para a manifestação da infecção que apresentam. Nos casos de gastrite ou úlceras, os sintomas são: dor abdominal ou epigástrica, náuseas ou vômitos e dispepsia. Contudo, para identificar a infecção, faz-se necessária a realização de exames laboratoriais (COELHO FMMC, 2013).

O diagnóstico da infecção por $H$. pylori pode ser feito por meio de cultivos microbiológicos, análises histopatológicas, teste de respiração com carbono marcado, teste da urease em biópsias, testes sorológicos e através de técnicas moleculares (reação em cadeia polimerase - PCR), segundo Vargas LJ, et al. (2019); testes por saliva compõem a lista de exames de diagnóstico para $H$. pylori (TEIXEIRA TF, et al., 2016). Os testes respiratórios com ureia marcada com isótopo estável e o PCR são considerados os testes mais eficazes para a detecção do patógeno (VARGAS LJ, et al., 2019).

Além das amostras gástricas, essa bactéria é encontrada em diversos nichos na cavidade oral tal como biofilme dental supragengival, língua, saliva, amígdalas, bem como algumas condições patógenas não iniciadas por ele como úlceras aftosas e nas superfícies neoplásicas orais. Além disso, estabelece associação com algumas doenças extras gástricas, como lesões coronarianas, sugerindo que este microrganismo pode apresentar relação com outras importantes doenças sistêmicas (SANTOS MM, et al., 2015).

A presença da bactéria no suco gástrico possibilita a via de transmissão oral-oral através da deposição do microrganismo na boca por meio do vômito e refluxo esofágico, além de contribuir para a permanência de H. pylori no biofilme dental ou saliva. Desse modo, a cavidade oral serve como reservatório transitório ou permanente para esse micróbio (SANTOS MM, et al., 2015).

Pacientes com higiene oral deficiente manifestavam mais facilmente $H$. pylori na cavidade oral, em relação aos pacientes com boa higiene oral. Devido ao efeito antagonista de algumas bactérias do biofilme dental, alguns autores divergem quanto à transitoriedade do patógeno na cavidade oral, pois, segundo uma demonstração in vitro, elas podem inibir a colonização deste organismo na cavidade oral em contraposição a outros autores que detectaram esta bactéria em quase todos os pacientes dos seus estudos, considerando o Helicobacter pylori como parte da microbiota normal da cavidade oral (SANTOS MM, et al., 2015). 
As bactérias S. mutans, P. intermedia, Streptococcus oralis, Streptococcus mitis, Streptococcus mutans, Streptococcus sobrinus, Actinomyces naes/undii, Prevotella intermedia e Prevotella nigrescens, seriam capazes de sintetizar proteínas inibitórias semelhantes à bacteriocinas com grande atividade inibitória de crescimento de cepas do $H$. pylori. Embora as defesas do hospedeiro sejam influentes no processo e os microambientes do biofilme supragengival e sublingual sejam distintos, a sobrevivência no biofilme dental é possível (SANTOS MM, et al., 2015). Devido a isso, pesquisadores afirmam que a boca é a mais provável fonte de disseminação e reinfecção do patógeno (MAZZOLENI DS, 2019).

De acordo com Santos MM, et al. (2015), o H. pylori é detectado com frequência em sítios orais como o dorso da língua, associado a alguma patologia desta área. As lesões aftosas demonstraram associação positiva entre essa bactéria e a úlcera, embora nem sempre os pacientes que testaram positivo para o patógeno em cavidade oral e em estômago manifestaram a presença dele em ambos os meios (MEDINA ML, et al., 2017).

A incidência de Helicobacter pylori na saliva é menor quando comparada a placa dentária. Este fato se justifica por a placa dentária permitir a aderência do microrganismo a superfícies fixas, enquanto que na saliva o seu fluxo contínuo pode interferir nos resultados das amostras, gerando uma alteração da carga bacteriana pela variação de acordo com o momento de coleta (ANAND PS, et al., 2014).

As pesquisas na área da Periodontia evidenciaram que a relação entre doença periodontal e presença de $H$. pylori é diretamente proporcional (JÚNIOR EGJ, et al., 2014). Isso ocorre devido às condições patológicas periodontais como a gengivite, de acordo com Santos MM, et al. (2015); periodontite e periimplantites, que também representam problemas associados às alterações na microbiota em torno dos elementos dentais, raízes e implantes e, consequentemente, alteram a composição salivar que banha as estruturas da cavidade oral (OLIVEIRA MC, et al., 2015). Quando a presença da bactéria é detectada na saliva das pessoas com periodonto sadio, dificilmente a apresentam também nos biofilmes gengivais (JÚNIOR EGJ, et al., 2014).

Há maior frequência de detecção de H. pylori na microbiota oral de pacientes com periodontite quando comparados a indivíduos sem periodontite. Assim, a formação de bolsas periodontais e inflamações favorecem a colonização por $H$. pylori na cavidade bucal, embora as condições anaeróbias das bolsas não sejam essenciais para o seu estabelecimento. Com isso, pacientes diabéticos, por estarem incluídos no fator de risco para a doença periodontal, estão mais propensos ao alojamento da bactéria em boca (JÚNIOR EGJ, et al., 2014).

A doença periodontal é considerada um fator que propicia a instalação e sobrevivência da Helicobacter pylori no biofilme oral devido à formação de um nicho mais favorável que é elevado quantitativamente conforme o avanço da doença. Com isso, a bactéria pode ser detectada em amostras sub e supragengivais, nas mucosas e principalmente na língua. Logo, os pacientes que se beneficiarem do tratamento periodontal terão o controle mais efetivo da proliferação da bactéria em ambiente oral em relação aos que não tiverem esse controle (JÚNIOR EGJ, et al., 2014).

O biofilme dentário é considerado o principal precursor das doenças periodontais inflamatórias se não for removido corretamente. A higienização da superfície do elemento dental pode ser realizada pelo próprio individuo por métodos que visam à desorganização dos microorganismos que se aderiram. Estes métodos consistem em escovações, uso de dentifrícios, utilização de limpadores de língua e o uso adequado do fio dental. No entanto, a autonomia do paciente para a realização desse conjunto de ações que visam o controle do biofilme dental só será possível e efetivo mediante motivação, encorajamento à autonomia e a instrução por parte de um Cirurgião-Dentista para a correta orientação de acordo com cada caso (SILVA AS, et al., 2011).

Ademais, devido à complexidade do tratamento do patógeno, deve-se empregar a associação de antibióticos somados a supressores ácidos para a efetivação da terapia. Cerca de $20 \%$ dos pacientes necessitam repetir o tratamento. Por isso, é necessário analisar os fatores mais importantes para o sucesso do tratamento: resistência bacteriana e adesão do paciente ao tratamento. Outros fatores relacionados são: 
fatores geográficos, raça, uso prévio dos medicamentos, doses de inibidor de bomba de próton e a sensibilidade microbiana, que é divergente de acordo com a localização (GOMES LC e LAGO APMC, 2014).

Alguns autores evidenciaram que a monoterapia antibiótica e a terapia dupla com bismuto e Inibidores de Bomba de Prótons (IBP) são pouco eficazes sobre a bactéria. Já a terapia tríplice composta por bismuto associado à IBP e dois antibióticos (claritromicina, amoxicilina ou metronidazol) se mostrou a melhor alternativa devido ao menor custo e boa tolerância medicamentosa por parte dos pacientes. Por fim, a terapia quádrupla com bismuto, metronidazol, tetraciclina e anti-secretor gástrico, apesar de comprovada a eficácia, seus efeitos adversos dificultam a adesão ao tratamento (GOMES LC e LAGO APMC, 2014).

Segundo Magalhães et al. (2016), a condução do tratamento para as infecções por Helicobacter pylori, mais comumente, se dá pela combinação de amoxicilina, claritromicina, furazolidona, metronidazol e tetraciclina com bismuto ou próton inibidor da bomba. Entretanto, a adesão do paciente ao tratamento é dificultada devido ao seu alto custo ou ainda a resistência bacteriana.

Alternativa terapêutica da terapia tríplice, desenvolvida no Brasil, com lanzoprazol, amoxicilina e claritromicina é eficaz para países em desenvolvimento devido ao seu alto nível de erradicação, além de ser bem tolerável pela população (GOMES LC e LAGO APMC, 2014).

Para a halitose que pode ser causada pelos distúrbios gástricos oriundos da infecção por Helicobacter pylori no indivíduo infectado, pode-se realizar a administração de omeprazol, amoxicilina e claritromicina (GONÇALVES AFO, 2019).

Num estudo de Magalhães CG, et al. (2016), foi confirmada a eficácia do uso de extratos da planta Maytenus salicifolia contra patógenos orais e úlceras estomacais. Essa planta é conhecida como "cafezinho" no estado brasileiro de Minas Gerais e já é utilizada na medicina popular após sua decocção para amenizar sintomas de alergias na pele e coceira.

Ademais, um estudo realizado com pacientes infectados por Helicobacter pylori demonstrou a importância do controle do biofilme oral uma vez que, mais de $80 \%$ dos pacientes que não tiveram o acompanhamento odontológico, sofreram reinfecção. Em contrapartida, dos pacientes que foram acompanhados por um cirurgião-dentista, apenas 19,6\% foram reinfectados (PATARO AL et al., 2016).

Para verificar se houve eliminação da $H$. pylori deve-se realizar novamente os testes após quatro semanas do fim do tratamento. É necessária a realização de mais de uma biópsia durante o exame endoscópico a fim de garantir maior precisão do resultado. Os exames mais invasivos são mais sensíveis e a realização do teste da urease no momento do exame garante mais rapidez ao resultado, que deverá passar por testes de histologia e cultura para evidenciar com maior sensibilidade a reação da bactéria frente aos antibióticos utilizados (GOMES LC e LAGO APMC, 2014).

Diversos trabalhos experimentais em humanos estão sendo desenvolvidos para a erradicação da infecção por Helicobacter pylori através de uma vacina anti-H. Pylori. A vacina ainda não está disponível, então é necessário que a prevenção seja mantida por meio de hábitos saudáveis, mesmo naqueles que já foram diagnosticados ou são hospedeiros do patógeno. Assim, será possível a redução da infecção e a sua reincidência na população mundial (TEIXEIRA TF, et al., 2016).

\section{CONSIDERAÇÕES FINAIS}

O Helicobacter pylori pode apresentar-se na cavidade oral como parte de uma população resultante do meio ao qual o hospedeiro está inserido. Pode estar presente em meio gástrico e bucal, simultaneamente ou não; no entanto, quando presente na cavidade oral, esta pode servir como meio de transmissão por via oral-oral ou ainda ser responsável pela reinfecção do paciente. Desse modo, é essencial o conhecimento e participação do Cirurgião-dentista na prevenção e no tratamento da infecção por Helicobacter pylori, através da orientação ao paciente quanto aos cuidados com a saúde e higienização bucal, bem como a efetivação do controle do biofilme oral no tratamento periodontal. 


\section{REFERÊNCIAS}

1- ANAND PS, et al. Role of dental plaque, saliva and periodontal disease in Helicobacter pylori infection. World J. Gastroenterol, 2014; 20(19): 5639-5653.

2- BARBOSA JA, SCHINONNI MI. Helicobacter pylori: Associação com o câncer gástrico e novas descobertas sobre os fatores de virulência. Revista de Ciências Médicas e Biológicas, 2010; 10(3): 254-262.

3- COELHO FMMC. Helicobacter pylori eficácia da terapêutica. Dissertação (Mestrado em Medicina) - Universidade da Beira do Interior, Covilhã, 2013; 42p.

4- DRUMM B, ROWLAND M. Por que o Helicobacter pylori está desaparecendo? Mais perguntas do que respostas. Jornal de Pediatria, 2011; 87(5): 369-70.

5- FERNANDES MJB. H. pylori - a fisiopatologia da doença. Dissertação (Mestrado Integrado em Medicina) Universidade do Porto, Porto, 2016; 35p.

6- GOMES LC, LAGO APMC. Análise e Revisão de Métodos para Diagnóstico do Helicobacter Pylori. Rev Acadêmica Oswaldo Cruz, 2014; 1(2): 5-7.

7- GONÇALVES AFO. Como a halitose afeta a vida e o bem-estar do indivíduo. Dissertação (Mestrado em Medicina Dentária) - Instituto Universitário de Ciências da Saúde, Gandra, 2019; 35p.

8- JÚNIOR EGJ, et al. Helicobacter pylori em boca: epidemiologia e associação com doenças bucais. Arch Health Invest, 2014; 3(2): 48-56.

9- MAGALHÃES CG, et al. Maytenus salicifolia (Celastraceae): Evaluation of the Activity of Extracts and Constituents against Helicobacter pylori and Oral Pathogenic Microoganisms. Rev Virtual Quim, 2016; 10(10): 01-10.

10-MAZZOLENI DS. Estomatite Aftosa Recorrente: Papel do Helicobacter pylori e de outros Fatores de Risco e de Proteção. Dissertação (Pós-graduação: Ciências em Gastroenterologia e Hepatologia) - Universidade Federal do Rio Grande do Sul, Porto Alegre, 2019; 40p.

11-MEDINA ML, et al. Correlation between virulence markers of Helicobacter pylori in the oral cavity and gastric biopsies. Arq Gastroenterol, 2017; 54(3): 217-221.

12-OLIVEIRA MC, et al. Peri-implantite: etiologia e tratamento. Revista Brasileira de Odontologia, 2015; 72(1): 96-99.

13-PARDO MLE, et al. Prevalência da infecção por Helicobacter pylori e de parasitoses intestinais em crianças do Parque Indígena do Xingu. Jornal de Pediatria, 2011; 87(5): 393-898.

14-PATARO AL, et al. Frequency of periodontal pathogens and Helicobacter pylori in the mouths and stomachs of obese individuals submitted to bariatric surgery: a cross-sectional study. J Appl Oral Sci, 2016; 24(3): 229-238.

15-PEREIRA MF, et al. Helicobacter pylori em boca: relação entre saúde e doença. Arch Health Invest 2014; 3:(3): 8182.

16-RODRIGUES JA, et al. Genes de virulência em Helicobacter pylori: componentes estruturais e métodos de detecção. SAÚDE \& CIÊNCIA EM AÇÃO - Revista Acadêmica do Instituto de Ciências da Saúde, 2017; 3(2): 10-22.

17-SANTOS FG. Farmacoterapia na erradicação da infecção por Helicobacter pylori. Monografia (curso bacharelado em Farmácia) - Faculdade Maria Milza, Governador Mangabeira, 2017; 58p.

18-SANTOS MM, et al. A Importância da Presença de Helicobacter Pylori na Cavidade Oral. Braz J Periodontol, 2015; 25(3): 57-62.

19-SILVA AS, et al. Controle mecânico do biofilme dental. Revista Gestão \& Saúde, 2011; 2(2): 1-6.

20-SOYFOO DM, et al. Novos genótipos de Helicobacter pylori VacA região-D identificada a partir de cepas globais. BMC Molecular and Cell Biology, 2021; 22(4): 1-12.

21-TABILE PM, et al. Prevalência De Helicobacter Pylori Salivar E Associaçâo Com Fatores Sócio-Econômicos. Blucher Medical Proceedings, 2014; 1(5): 66.

22-TEIXEIRA TF, et al. Helicobacter pylori: infecção, diagnóstico laboratorial e tratamento. Percurso Acadêmico, 2016; 6(12): 481-504.

23-VARGAS LJ, et al. Métodos para diagnósticos para detecção da infecção pelo h. pylori: revisão sistemática. Pará Research Medical Journal, 2019; 3(2): 1-6. 